\title{
Employment Among People Who Use Drugs: A NEW ARENA FOR RESEARCH AND INTERVENTION?
}

\author{
Lindsey Richardson, MPhil ${ }^{\mathrm{a}, \mathrm{b}}$, Susan G. Sherman, PhD., MPH' ${ }^{\mathrm{c}}$, Thomas Kerr, PhD. ${ }^{\mathrm{a,d}}$
}

a) British Columbia Centre for Excellence in HIV/AIDS, St. Paul's Hospital, 608-1081 Burrard Street, Vancouver, BC, Canada, V6Z 1 Y6

b) Department of Sociology, Oxford University, Manor Road Building, Manor Road, Oxford, United Kingdom, UK, OX1 3UQ

c) Johns Hopkins Bloomberg School of Public Health, Department of Epidemiology, 615 N. Wolfe Street, E6543, Baltimore, MD, USA, 21205

d) Department of Medicine, University of British Columbia (Division of AIDS), Room 10203 - 2775 Laurel St., Vancouver, BC, Canada, V5Z 1M9

Send correspondence to:

Thomas Kerr, Ph.D.

BC Centre for Excellence in HIV/AIDS

608-1081 Burrard Street, Vancouver, B.C.

CANADA V6Z 1 Y6

Tel: +1 (604) 806-9116Fax : +1(604) 806-9044

Email: uhri-tk@cfenet.ubc.ca

Keywords: employment, illicit drug use, labour market participation, social determinants of health, stigma

Word count: 1499 
Employment is widely recognized as a robust determinant of health. For this and other political, social and economic reasons, governments throughout the world invest heavily in efforts to promote employment and reduce unemployment among the general population. Unfortunately, when it comes to people who use illicit drugs, employment is typically relegated to the status of a second order problem, and the role of employment, particularly for non-treatment enrolled individuals, has been largely ignored in the scientific literature. The limited attention that employment among active illicit drug users has received has focused primarily on how drug use affects labour market participation in large representative samples, on whether or not people enrolled in addiction treatment become employed as an indication of a successful rehabilitation process, or occasionally on employment status as a risk factor for negative health outcomes. While most individuals who use illicit drugs are employed (French et al., 2001), chronic unemployment and socio-economic vulnerability are fundamental, daily and intractable challenges for many (Seddon, 2006). This is often particularly the case for individuals with high intensity illicit drug use patterns, who face multiple social and economic disadvantages or who experience concurrent health problems. Generally confined to the margins of the labour market, it is for these individuals that finding viable income generation may pose the greatest challenge, but for whom it may usher the greatest benefit. Given the well-established link between employment and health, and widespread concern for levels of unemployment, particularly in times of economic hardship, why is labour market participation not more emphasized, or emphasized in the same way, among vulnerable people who use illicit drugs?

Part of the answer may be because of implicit assumptions about the capacity, interest or willingness of people who use illicit drugs, particularly people who inject drugs (IDUs), to engage with the labour market at all. And while an inability or unwillingness to pursue employment may be relevant for some, empirical data from a population of predominantly inner-city IDUs from Vancouver suggests that approximately $30 \%$ are participating in the labour market at any given time (Richardson et al., 2010). There is the additional question of the stigma attached to drug use and potential discrimination among employers (Grover \& Paylor, 2010), evidenced by the spread of mandatory drug testing as a condition for 
job eligibility or tenure (Tunnell, 2004), even for employees who do not hold safety- or security-sensitive jobs. It would also be a careless omission to overlook the impact that having a criminal record, a very common state of affairs for highly vulnerable illicit drug users, can have in severely limiting the licit employment options of individuals (Pager, 2003).

This begs the question of what potential benefits might accrue from targeted employment and skills development in a context of potentially active drug use. In a rare example, the development of a viable, alternative income source for sex workers who also used illicit drugs was shown to lower high-risk behaviour, including decreases in the median number of sex partners per month and daily drug use (Sherman et al., 2006). Likewise, there are instances of peer-led initiatives in various settings that provide temporary and low-threshold employment opportunities for illicit drug users, including those that involve drug users in the delivery of health programs or in the execution of research (Kerr et al., 2006, Latkin, Sherman \& Knowlton, 2002, Hayashi et al., in press). While lauded by participants, the impact of these initiatives on health and social outcomes among drug users, including their potential to facilitate subsequent socio-economic benefit through the acquisition of skills, pro-social roles and enhanced beliefs about employability, has not been thoroughly explored. In other research on the income generating activities of IDUs, it has been demonstrated that many individuals would give up high-risk, illegal income generation if they didn't need money for drugs (DeBeck et al., 2007). One way to shift incentives away from illegal income generation is therefore the traditional approach of attempting to increase drug use cessation by enrolling more people in addiction treatment. Given the complexity of drug dependence and high rates of substance use relapse, an alternative, and potentially more pragmatic way to do so, would be to incentivise low-threshold legal income generating options.

One area that has shown some promise is that of employment-based abstinence reinforcement, or contingency management (CM) approaches (see Silverman et al., 2007 for a review). These interventions financially reinforce workplace attendance and/or drug abstinence by making employment access or wages contingent on biologically verified drug abstinence, usually through the provision of drug-free 
urine screens. Financial reinforcement has been shown to support employment participation and decrease drug use (DeFulio et al., 2009). These programs have likewise demonstrated that adults with long histories of chronic unemployment and drug dependence can acquire critical employment skills over relatively short periods of time (Dillon et al., 2004). A lack of widespread adoption of CM approaches has been attributed to issues of feasibility, an inability to address underlying addiction issues, potentially negative side effects and philosophical objections (Kirby et al., 2006). Furthermore, as with other CMbased interventions, questions remain regarding the durability of the effects of employment-based abstinence reinforcement; no employment-based reinforcement study has reliably produced changes that persist after the reinforcement is removed (Silverman et al., 2007). While CM approaches have shown temporarily improved outcomes, a broader range of employment-based alternatives that do not require abstinence from drug use should be explored.

Maintaining that socio-economic integration for non-employed people who use illicit drugs must follow a rigid sequence - that individuals must first abstain from use and then find work - disregards research that suggests that many people continue to participate in mainstream social and economic activities while chronically using highly addictive drugs (see, for example, Harling, 2007), and that addiction is for many a chronic relapsing condition. What if, instead of an outcome of successful treatment, employment was approached as a potentially stabilizing force in people's lives that could precede drug use cessation? What if it were conceptualised not only as economically productive activity, but also as a socially important, psychologically useful and health promoting one, regardless of whether or not an individual is actively using illicit drugs? The power of being a productive member of society and concomitant enhancement of self-esteem - could powerfully influence drug cessation in a sustainable way. In addition being a legal source of income, employment brings with it improved physical and mental health and a myriad of benefits that come with having regular structured activity, increased social contact and integration, reduced stigma, decreased levels of stress and increased social status (Bartley, 1994). For those able and willing to engage with the labour market, the potential benefits are far reaching. 
It is crucial that we acknowledge that what people do to their bodies is conditioned by how they live their lives. We know that among vulnerable illicit drug users there are myriad potential social, economic and health advantages to accessing viable, licit income generating activity. Beyond this, the importance of viewing illicit drug users in more than a stigmatizing, one-dimensional conceptualization of the 'person-as-user' cannot be overstated. Focusing on employment among people who use illicit drugs speaks to the structural importance of income generation to multiple aspects of people's lives, including, but not limited to, their drug use. The few but compelling studies of the benefits of viable income generation options among active, high-intensity illicit drug users mentioned above call for a new research agenda on employment focused on this population. This agenda should include intervention development and evaluation for initiatives that vary levels of job structure and job tenure requirements, ranging from low-threshold options for highly active illicit drug users to full time, conventional labour market participation. This agenda should further include the impact of informal or under-the-table work, which may provide access to income generation that is easier to obtain, more flexible, or more accessible, but may also expose vulnerable individuals to unsafe work environments where work safety and protection standards are sub-standard or nonexistent. A crucial component of this research will also be documenting experiences with labour market participation and other income generating activities, as the perspectives of people who use illicit drugs on the role of money and employment in their lives have not yet been fully explored. This is particularly the case given the connection between job quality and mental health; access to work that is characterized by inadequate pay, objectionable duties, low satisfaction or work insecurity may have a deleterious rather than beneficial effect. It is not merely the quantity of income generating opportunities, but also the quality of opportunity that is important. Of further relevance in the current economic climate is the need to design creative income generating structures and opportunities for vulnerable drug users that are not merely social programs, but self-sustaining labour market participation models. Indeed, increasing the socio-economic security of people who use illicit drugs through viable income generating activity has the potential not only to decrease harm, but also to produce vast benefits for individuals, families, neighbourhoods, communities and society at large. 


\section{ACKNOWLEDGEMENTS}

Lindsey Richardson is supported by doctoral awards from the Pierre Elliott Trudeau Foundation and the Social Sciences and Humanities Research Council of Canada. Thomas Kerr is supported by the Michael Smith Foundation for Health Research and the Canadian Institutes of Health Research.

These funding sources had no involvement in the conceptualization this study, or in the decision to submit this paper for publication. 


\section{REFERENCES}

Bartley, M., (1994). Unemployment and ill health: Understanding the relationship. Journal of Epidemiology and Community Health, 48, 333-337.

DeBeck K., Shannon K., Wood E., Li K., Montaner J., Kerr T., 2007. Income generating activities of people who inject drugs. Drug and Alcohol Dependence, 91, 50-56.

DeFulio, A., Donlin, W.D., Wong, C.J., Silverman, K. (2009). Employment-based abstinence reinforcement as a maintenance intervention for the treatment of cocaine dependence: a randomized controlled trial. Addiction, 104, 1530-1538.

Dillon E.M., Wong C.J., Sylvest C.E., Crone-Todd D.E., Silverman K. (2004). Computer-based typing and keypad skills training outcomes of unemployed injection drug users in a therapeutic workplace. Substance Use \& Misuse, 39, 2325-2353.

French, M.T., Roebuck, C. and Alexandre, P.K. (2001). Illicit Drug use, Employment, and Labor Force Participation. Southern Economic Journal, 68, 349-368.

Grover, C. and Paylor, I. (2010). No one written off? Welfare, work and problem drug use. DrugsEducation Prevention and Policy, 17, 315-332.

Harling, M.R. (2007). The place and meaning of 'controlled', illicit substance use in the private lives of a group of individuals. Journal of Substance Use, 12, 1-12.

Hayashi, K., Fairbairn, N., Suwannawong, P., Kaplan, K., Wood, E., Kerr, T. Collective empowerment while creating knowledge: a description of a community-based participatory research project with drug users in Bangkok, Thailand. Substance Use \& Misuse (in press).

Kerr, T., Small, W., Peeace, W., Douglas, D., Pierre, A., Wood, E. (2006). Harm reduction by a "userrun" organization: A case study of the Vancouver Area Network of Drug Users (VANDU). International Journal of Drug Policy, 17, 61-69.

Kirby, K.C., Benishek, L.A., Dugosh, K.L., Kerwin, M.E. (2006). Substance abuse treatment providers' beliefs and objections regarding contingency management: Implications for dissemination. Drug and Alcohol Dependence, 85, 19-27.

Latkin C.A., Sherman S.G., Knowlton A. (2002). HIV prevention among drug users: outcome of a network-oriented peer outreach intervention. Health Psychology, 22, 332-339.

Pager, D. (2003). The Mark of a Criminal Record. American Journal of Sociology, 108, 937-975.

Richardson, L., Wood, E., Li, K., and Kerr, T. (2010). Factors associated with employment among a cohort of injection drug users. Drug and Alcohol Review, 29, 293-300.

Sherman, S.G., German, D., Cheng, Y., Marks, M., Bailey-Kloche, M. (2006). The evaluation of the JEWEL project: An innovative economic enhancement and HIV prevention intervention study targeting drug using women involved in prostitution. AIDS Care, 18, 1-11. 
Silverman, K., Wong, C.J., Needham, M., Diemer, K.N., Knealing, T., Crone-Todd, D., Fingerhood, M., Nuzzo, P., Kolodner, K. (2007). A Randomized Trial of Employment-Based reinforcement of cocaine abstinence in injection drug users. Journal of Applied Behavior Analysis, 40, 387-410.

Tunnell, K. D., (2004). Pissing on Demand: Workplace Drug Testing and the Rise of the Detox Industry. New York: New York University Press. 